\title{
Analyses of apoptosis and DNA damage in bovine cumulus cells after in vitro maturation with different copper concentrations: consequences on early embryo development
}

\author{
D.E. Rosa ${ }^{3,5}$, J.M. Anchordoquy $2,3,5$, J.P. Anchordoquy 2,3 , M.A. Sirini' ${ }^{2}$, J.A. Testa ${ }^{2}$, G.A. Mattioli ${ }^{3}$ \\ and C.C. Furnus ${ }^{1,2,4}$ \\ Instituto de Genética Veterinaria Prof. Fernando N. Dulout (IGEVET), Facultad de Ciencias Veterinarias, Universidad \\ Nacional de La Plata - CONICET; Cátedra de Fisiología, Laboratorio de Nutrición Mineral, Facultad de Ciencias Veterinarias, \\ Universidad Nacional de La Plata; Cátedra de Citología, Histología y Embriología 'A', Facultad de Ciencias Médicas, \\ Universidad Nacional de La Plata, La Plata, Buenos Aires, Argentina
}

Date submitted: 13.10.2015. Date revised: 23.06.2016. Date accepted: 01.07.2016

\section{Summary}

The aim of this study was to investigate the influence of copper (Cu) during in vitro maturation (IVM) on apoptosis and DNA integrity of cumulus cells (CC); and oocyte viability. Also, the role of CC in the transport of $\mathrm{Cu}$ during IVM was evaluated on oocyte developmental capacity. Damage of DNA was higher in CC matured without $\mathrm{Cu}(0 \mu \mathrm{g} / \mathrm{dl} \mathrm{Cu}, P<0.01)$ with respect to cells treated with $\mathrm{Cu}$ for cumulus-oocyte complexes (COCs) exposed to $0,20,40$, or $60 \mu \mathrm{g} / \mathrm{dl} \mathrm{Cu}$ ). The percentage of apoptotic cells was higher in $\mathrm{CC}$ matured without $\mathrm{Cu}$ than in $\mathrm{CC}$ matured with $\mathrm{Cu}$. Cumulus expansion and viability of CC did not show differences in COC treated with $0,20,40$, or $60 \mu \mathrm{g} / \mathrm{dl} \mathrm{Cu}$ during IVM. After in vitro fertilization (IVF), cleavage rates were higher in COC and DO + CC (denuded oocytes + CC) with or without $\mathrm{Cu}$ than in DO. Independently of CC presence (COC, DO + CC or DO) the blastocyst rates were higher when $60 \mu \mathrm{g} / \mathrm{dl} \mathrm{Cu}$ was added to IVM medium compared to medium alone. These results indicate that $\mathrm{Cu}$ supplementation to IVM medium: (i) decreased DNA damage and apoptosis in CC; (ii) did not modify oocyte viability and cumulus expansion; and (iii) improved subsequent embryo development up to blastocyst stage regardless of CC presence during IVM.

Keywords: Apoptosis, DNA damage, Early development, Minerals

\footnotetext{
${ }^{1}$ All correspondence to: C.C. Furnus. Instituto de Genética Veterinaria Prof. Fernando N. Dulout (IGEVET), Facultad de Ciencias Veterinarias, Universidad Nacional de La Plata - CONICET, calle 60 y 118 s/n, CP (1900), La Plata, Buenos Aires, Argentina Tel:/Fax: +54 02214211799. E-mail: cfurnus@fcv.unlp.edu.ar

${ }^{2}$ Instituto de Genética Veterinaria Prof. Fernando N. Dulout (IGEVET), Facultad de Ciencias Veterinarias, Universidad Nacional de La Plata - CONICET, calle 60 y 118 s/n, CP (1900), La Plata, Buenos Aires, Argentina.

${ }^{3}$ Cátedra de Fisiología, Laboratorio de Nutrición Mineral, Facultad de Ciencias Veterinarias, Universidad Nacional de La Plata, calle 60 y 118 s/n, CP (1900), La Plata, Buenos Aires, Argentina.

${ }^{4}$ Cátedra de Citología, Histología y Embriología 'A', Facultad de Ciencias Médicas, Universidad Nacional de La Plata, calle 60 y 118 s/n, CP (1900), La Plata, Buenos Aires, Argentina. ${ }^{5}$ These authors made an equal contribution to this paper.
}

\section{Introduction}

Hypocuprosis is the predominant deficiency that globally affects grazing cattle Ramirez et al., 1998). National Animal Health Monitoring Service categorized 40.6\% of United States beef cattle as copper deficient (Dargatz et al., 1999). Ramirez and colleagues (1998) reported similar values in Salado River Basin (Argentina), an area of $55793 \mathrm{~km}^{2}$ with $6.5 \times 10^{6}$ beef cattle (Dillon, 1992). Copper deficiency is evidenced by different clinical signs such as pale coat; anemia; spontaneous fractures; poor capillary integrity; myocardial degeneration; hypomyelinization; poor reproductive performance; reduce resistance to infectious disease; diarrhea, and generalized ill-health causing severe economic losses (Tessman et al., 2001).

The mammalian cumulus-oocyte complex (COC) and its extracellular matrix are involved in several 